
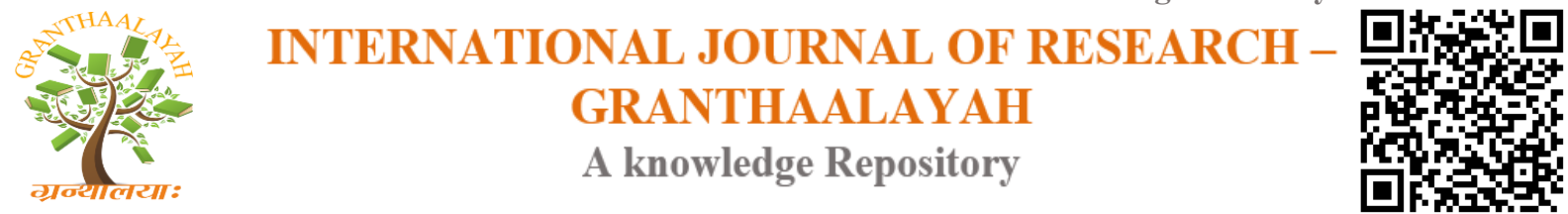

Science

\title{
CONTRIBUTION OF WOMEN IN HYDROLOGICAL RESEARCH
}

\author{
C. P. Kumar ${ }^{* 1}$ \\ ${ }^{* 1}$ Scientist 'G', National Institute of Hydrology, Roorkee - 247667, Uttarakhand, INDIA
}

\begin{abstract}
Women play a central part in the provision, management and safeguarding of water. This pivotal role of women as providers and users of water and guardians of the living environment has seldom been reflected in institutional arrangements for the development and management of water resources. Acceptance and implementation of this principle requires positive policies to address women's specific needs and to equip and empower women to participate at all levels in water resources programmes, including decision-making and implementation. The objective of this paper is to highlight some of the recent contribution of women in the field of Hydrology.
\end{abstract}

Keywords:

Hydrology, Women, Gender, Climate, Groundwater, Surface water.

Cite This Article: C. P. Kumar, "CONTRIBUTION OF WOMEN IN HYDROLOGICAL RESEARCH" International Journal of Research - Granthaalayah, Vol. 4, No. 1 (2016): 14-26.

\section{INTRODUCTION}

Gender roles have traditionally confined women and girls to activities taking place within the household: caring for others, cooking, cleanup, and so on. Leadership roles and higher education have been reserved for men. The traditional gender roles are now-a-days considered restrictive by both sexes, compounded by the fact that adult females are compensated less than men in similar employment areas.

Gender refers to different roles, rights, and responsibilities of men and women and dealings between them. Gender does not merely mention to women or human beings, but by the way their qualities, behaviours, and identities are seen through the process of acculturation. Gender is generally associated with unequal power and access to choices and resources. The different positions of women and men are influenced by historical, religious, economic and cultural realities. These relations and responsibilities can and do change over time.

The problem of gender imbalance at higher hierarchical levels in many fields like in science is not anymore due to explicit and deliberate discrimination, but it is also not completely due to objective explainable factors; invoked factors typically include motherhood or the fear of 
parents. Explanations like a lack of interest for hard science or for powerful positions do, all the same, still appear in many related discussions. At international level, activities over the last two decades have led to a clear realization that progress in many fields depends on the progress of adult females. It has become more and more accepted that women should act as a significant character in water management and that this purpose could be heightened through the strategy of gender mainstreaming.

\section{WOMEN AND WATER}

Water is the source of life and human civilization. The future of the world depends on the use we make of this finite and vulnerable resource today. It is necessary to promote a new attitude to water, based not only on scientific knowledge, but also on cultural and ethical values. Over the years, women have accumulated an impressive store of environmental wisdom. Women have always been the ones to find water, choosing their sources according to certain criteria such as accessibility, availability, distance, time, quality and use. Women's knowledge and experience in the supply and use of water is invaluable, and many problems could be avoided if women were consulted on such items as local sources of water, the location of a well or the design of a pump. Furthermore, women are invaluable as environmental educators and communicators both within the family and the community. Involving women in water and sanitation programmes would greatly contribute to protecting our precious water resources for future generations and to changing our attitudes to health and hygiene.

Women in developing countries are often referred to as water suppliers and water managers. Daily collecting of water is almost always the responsibility of the women, and it is the women who decide on how it is to be used within the household. However, women are mostly absent from the professional sector. It is essential that women become more involved as advisers, planners, scientists, engineers, in all areas from academia to government services.

Three surveys, two by WMO in 1997 and 2001 and one by the SIDS (Small Island Developing States) - Caribbean Project in 2002, show that women are under-interpreted in the National Meteorological and Hydrological Services (NMHSs) of the Caribbean: about 15\% of professional staff (e.g. operations, research, management) and about 30\% of support staff (e.g. technicians, observers) are women. In comparison, the same numbers are about $50 \%$ and $50 \%$ in Europe; $30 \%$ and $50 \%$ in Asia; 30\% and 25\% in Latin America; $20 \%$ and 20\% in North America; and $15 \%$ and $15 \%$ in Africa. As the time span of the surveys are relatively short, it is not possible to draw definitive conclusions (WMO - MeteoWorld, 2008).

Nigerian Meteorological Service employed its first female meteorologist in 1975 but today it has 40 trained female meteorologists and hydrologists. Upto 2000, there were no women at the directorate level, but in 2003 there were 4 women in the 12-person management team in the Nigerian Meteorological Agency (WMO, 2003).

In the past, few women showed interest in the sphere of research like in Hydrology. Very few articles by women were printed in past journals, but recent editions of different journals feature many women's work in Hydrology. Now many female hydrology staff members are publishing 
papers, books, attending conferences/seminars and receiving prizes. The aim of this article is to highlight the contribution of females in research in the field of Hydrology.

\section{CONTRIBUTION OF WOMEN IN HYDROLOGICAL RESEARCH}

Both men and women share responsibilities relating to water. But the gender division of labour within societies determines who has control over its use. Balanced attention to the genderdimension optimizes social and economic development and reduces competition and conflicts over water. Many countries have recognized the benefits of involving women in all aspects of their water and sanitation programs. Therefore, most government guidelines, project designs and program policies now incorporate a gender dimension but not at the implementation level. Thus, the promotion of a gender balance is still lacking (WMO Bulletin, 2003).

It is not enough to accord women paper rights through policy, law or institutional reform. Instead, the overall goal of any gender strategy for the water sector should be: to develop a framework which ensures that both women's and men's concerns and experiences are integral dimension of design, implementation and monitoring. Women can play a significant part in every field like that in the sphere of research as well. The significant and impressive role of women in the field of Hydrology has been highlighted below in the form of few recent contributions which may help in the promotion and realization of gender balance in the field of Hydrology. This list is just an indicative of the type of contribution of women in Hydrology during last few years $(2009-2015)$ and it is neither complete nor exhaustive.

I. Delpla et al. (2009): Besides climate change impacts on water availability and hydrological risks, the consequences on water quality is just beginning to be studied. This review aims at proposing a synthesis of the most recent existing interdisciplinary literature on the topic. After a short presentation about the role of the main factors (warming and consequences of extreme events) explaining climate change effects on water quality, the focus has been on two main points. First, the impacts on water quality of resources (rivers and lakes) modifying parameters values (physico-chemical parameters, micropollutants and biological parameters) are considered. Then, the expected impacts on drinking water production and quality of supplied water are discussed. The main conclusion which can be drawn is that a degradation trend of drinking water quality in the context of climate change leads to an increase of at risk situations related to potential health impact.

C. Isabella Bovolo et al. (2009): Groundwater is an important component of the freshwater system and its role is becoming even more prominent as the more accessible surface water resources become increasingly exploited to support increasing populations and development. Yet despite its significance, there has been comparatively little research conducted on groundwater relative to surface water resources, particularly in the context of climate change impact assessment. This focus issue has therefore been assembled to expand upon the currently limited knowledge of groundwater systems and their links with climate. Many of the papers included here explore the interrelated issues of groundwater resources, climate-related changes and vulnerabilities at a regional scale in different continents and globally. 
Sujana Dhar et al. (2009): India is a large developing country with nearly two-thirds of the population depending directly on the climate-sensitive sectors such as agriculture, fisheries and forests. A very well-calibrated Soil and Water Assessment Tool $\left(R^{2}=0 \cdot 9968\right.$, NSE $\left.=0.91\right)$ was exercised over the Kangsabati river watershed in Bankura district of West Bengal, India, for a year including monsoon and non-monsoon period in order to evaluate projected parameters for agricultural activities. Evapotranspiration, transmission losses, potential evapotranspiration and lateral flow to reach are evaluated from the years 2041-2050 in order to generate a picture for sustainable development of the river basin and its inhabitants. The projected climate change under various scenarios is likely to have implications on food production, water supply, biodiversity and livelihoods. India has a significant stake in scientific advancement as well as an international understanding to promote mitigation and adaptation. This requires improved scientific understanding, capacity building, networking and broad consultation processes. This paper is a commitment towards the planning, management and development of the water resources of the Kangsabati river by presenting detailed future scenarios of the Kangsabati river basin over the mentioned time period. The major findings of this paper were that of all the chosen projected parameters, transmission losses, soil water content, potential evapotranspiration, evapotranspiration and lateral flow to reach, display an increasing trend over the time period of years 2041-2050.

G. Freni et al. (2010): Due to the increased occurrence of flooding events in urban areas, many procedures for flood damage quantification have been defined in recent decades. The lack of large databases in most cases is overcome by combining the output of urban drainage models and damage curves linking flooding to expected damage. The application of advanced hydraulic models as diagnostic, design and decision-making support tools has become a standard practice in hydraulic research and application. Flooding damage functions are usually evaluated by a priori estimation of potential damage (based on the value of exposed goods) or by interpolating real damage data (recorded during historical flooding events). Hydraulic models have undergone continuous advancements, pushed forward by increasing computer capacity. The details of the flooding propagation process on the surface and the details of the interconnections between underground and surface drainage systems have been studied extensively in recent years, resulting in progressively more reliable models. The same level of was advancement has not been reached with regard to damage curves, for which improvements are highly connected to data availability; this remains the main bottleneck in the expected flooding damage estimation. Such functions are usually affected by significant uncertainty intrinsically related to the collected data and to the simplified structure of the adopted functional relationships. The present paper aimed to evaluate this uncertainty by comparing the intrinsic uncertainty connected to the construction of the damage-depth function to the hydraulic model uncertainty. In this way, the paper sought to evaluate the role of hydraulic model detail level in the wider context of flood damage estimation. This paper demonstrated that the use of detailed hydraulic models might not be justified because of the higher computational cost and the significant uncertainty in damage estimation curves. This uncertainty occurs mainly because a large part of the total uncertainty is dependent on depth-damage curves. Improving the estimation of these curves may provide better results in term of uncertainty reduction than the adoption of detailed hydraulic models.

Firdes Yenilmez et al. (2011): In this study, trends in selected water quality parameters in Eymir Lake over a period of 10 years are analyzed using the Mann-Kendall test. Analyzed water 
quality parameters are dissolved oxygen (DO), total phosphorus (TP), total suspended solids (TSS), and secchi depth (SD). In addition, trends in the yearly averages of precipitation, lake volume, and ambient temperature are examined. According to Mann-Kendall test results, precipitation, volume and ambient temperature values exhibit decreasing trends in 1998-2008. DO and TSS exhibit increasing trends while TP and SD have decreasing trends in Eymir Lake. The change in the volume of the lake has a significant impact on the trends of DO, TSS, and SD. These results indicate that, besides eutrophic conditions, water balance and drought conditions significantly impact the water quality of Eymir Lake.

Aditi S. Bhaskar et al. (2012): Urban water balances are generally unknown, yet they are necessary for assessing water availability in an urbanizing world and for understanding the effects of urbanization on the hydrologic cycle. They assessed the spatial and temporal variability of water balances of 65 watersheds in the Baltimore, MD, metropolitan area during Water Years 2001-2009. Each water balance term is quantified independently and includes both natural (precipitation, evapotranspiration, streamflow) and piped (sewer infiltration and inflow [I\&I], lawn irrigation, water supply pipe leakage) watershed inflows and outflows. The analysis also compares Gravity Recovery and Climate Experiment storage data with changes in storage calculated using the residual between watershed inflows and outflows. They found that when considering only natural water balance terms, the water balance residual (inflows minus outflows) increases with urbanization, largely as a result of the decrease in evapotranspiration as modeled by the land surface model Global Land Data Assimilation System/Noah. During wet years, the difference between urban and rural natural water balance residuals narrows because of increased urban streamflow. Excess water of the natural water balance in urban areas is largely exported by I\&I into wastewater collection pipes; for some urban watersheds this excess is greater than gauged annual streamflow. I\&I also outweighs piped inputs from lawn irrigation and water supply pipe leakage in the Baltimore area analysis. The net effect of piped flows on the urban water balance is a watershed export ranging between 300 and $465 \mathrm{~mm} / y e a r$, underscoring the importance of interactions between engineered water and wastewater infrastructure and natural water balance components.

Archana Sarkar et al. (2012): The Artificial Neural Network (ANN) approach has been successfully used in many hydrological studies especially the rainfall-runoff modeling using continuous data. The present study examines its applicability to model the event-based rainfallrunoff process. A case study has been done for Ajay river basin to develop event-based rainfallrunoff model for the basin to simulate the hourly runoff at Sarath gauging site. The results demonstrate that ANN models are able to provide a good representation of an event-based rainfall-runoff process. The two important parameters, when predicting a flood hydrograph, are the magnitude of the peak discharge and the time to peak discharge. The developed ANN models have been able to predict this information with great accuracy. This shows that ANNs can be very efficient in modeling an event-based rainfall-runoff process for determining the peak discharge and time to the peak discharge very accurately. This is important in water resources design and management applications, where peak discharge and time to peak discharge are important input variables.

Bridget R. Scanlon et al. (2012): Aquifer overexploitation could significantly impact crop production in the United States because $60 \%$ of irrigation relies on groundwater. Groundwater 
depletion in the irrigated High Plains and California Central Valley accounts for $\sim 50 \%$ of groundwater depletion in the United States since 1900. A newly developed High Plains recharge map shows that high recharge in the northern High Plains results in sustainable pumpage, whereas lower recharge in the central and southern High Plains has resulted in focused depletion of $330 \mathrm{~km}^{3}$ of fossil groundwater, mostly recharged during the past 13,000 years. Depletion is highly localized with about a third of depletion occurring in $4 \%$ of the High Plains land area. Extrapolation of the current depletion rate suggests that $35 \%$ of the southern High Plains will be unable to support irrigation within the next 30 years. Reducing irrigation withdrawals could extend the lifespan of the aquifer but would not result in sustainable management of this fossil groundwater. The Central Valley is a more dynamic, engineered system, with north/south diversions of surface water since the 1950s contributing to $\sim 7 \times$ higher recharge. However, these diversions are regulated because of impacts on endangered species. A newly developed Central Valley Hydrologic Model shows that groundwater depletion since the $1960 \mathrm{~s}$, totalling $80 \mathrm{~km}^{3}$, occurs mostly in the south (Tulare Basin) and primarily during droughts. Increasing water storage through artificial recharge of excess surface water in aquifers by up to $3 \mathrm{~km}^{3}$ shows promise for coping with droughts and improving sustainability of groundwater resources in the Central Valley.

A. Z. Aris and S. M. Praveena and others (2012): The aquifer of Manukan Island of Borneo, Malaysia had been found to be affected by seawater intrusion associated with excessive groundwater exploitation. This research attempted to characterize the chemistry of an impacted zone in the island using factor analysis (FA), cluster analysis (CA) and a hydrochemical model package (PHREEQC). The factor scores were used to plot the spatial map and to group the relationships among the monitoring wells using CA. The results of FA analysis revealed that the three main processes associated with the seawater intrusion event are aquifer salinization, cation exchange process and redox sequences. Output from the PHREEQC simulation was used to support the findings from the multivariate analysis.

Bridget R. Scanlon et al. (2013): Texas experienced the most extreme drought on record in 2011 with up to 100 days of triple digit temperatures resulting in record electricity demand and historically low reservoir levels. They quantified water and electricity demand and supply for each power plant during the drought relative to 2010 (baseline). Drought raised electricity demands/generation by $6 \%$, increasing water demands/consumption for electricity by $9 \%$. Reductions in monitored reservoir storage $<50 \%$ of capacity in 2011 would suggest drought vulnerability, but data show that the power plants were flexible enough at the plant level to adapt by switching to less water-intensive technologies. Natural gas, now $\sim 50 \%$ of power generation in Texas, enhances drought resilience by increasing the flexibility of power plant generators, including gas combustion turbines to complement increasing wind generation and combined cycle generators with $\sim 30 \%$ of cooling water requirements of traditional steam turbine plants. These reductions in water use are projected to continue to 2030 with increased use of natural gas and renewables. Although water use for gas production is controversial, these data show that water saved by using natural gas combined cycle plants relative to coal steam turbine plants is 25-50 times greater than the amount of water used in hydraulic fracturing to extract the gas.

Etishree Agarwal et al. (2013): The sustainable development and management of groundwater resource requires precise quantitative assessment based on scientific principle and modern 
techniques. In the present study, groundwater potential zone are delineated using remote sensing, geographical information system (GIS) and multi-criteria decision making (MCDM) techniques in Unnao district, Uttar Pradesh. The analytical network process (ANP) is a method that makes it possible for one to deal systematically, and includes the analytical hierarchy process (AHP) as a special case. The AHP and ANP are used to determine the weights of various themes and their classes for identifying the groundwater potential zone. These weights are applied in a linear combination to obtain five different groundwater potential zone in the study area, namely "very poor', 'poor', 'moderate', 'good' and 'very good'. It has been concluded that about $153.39 \mathrm{~km}^{2}$ area has very good groundwater potential which is only $3.37 \%$ of the total study area. However, the area having very poor groundwater potential is about $850 \mathrm{~km}^{2}$ which is about $19.63 \%$ of the study area. The area having good, moderate and poor groundwater potential is about $540.25,1135.5,1868.6 \mathrm{~km}^{2}$, respectively. The groundwater potential zone map was finally verified using the well yield data of 37 pumping wells, and the result was found satisfactory.

Justine He'nonin et al. (2013): Global flood management is a major issue for most cities which have to deal with worsening factors such as climate change and fast urban growth. Computer models have been used to model and understand urban flooding on a local scale in cities (25$50 \mathrm{~km}^{2}$ ). It has been practically impossible to model bigger cities in one go in sufficiently high resolution due to the heavy computations involved. The present paper describes a new modelling approach for urban flooding which allows modelling on large city scale $\left(1000 \mathrm{~km}^{2}\right)$ while keeping sufficient resolution, e.g. $5 \mathrm{~m}$ or $10 \mathrm{~m}$ grid. The multicell approach is applied for the city of Beijing for July 21st, 2012 flood event. Model results are compared to testimonials from the 2012 event. Comparison to traditional 2D urban flood computations shows that the multicell approach is much faster than standard detailed models while keeping a suitable level of precision.

Vincenza Notaro et al. (2013): Climate change and modification of the urban environment increase the frequency and the negative effects of flooding, increasing the interest of researchers and practitioners in this topic. Usually, flood frequency analysis in urban areas is indirectly carried out by adopting advanced hydraulic models to simulate long historical rainfall series or design storms. However, their results are affected by a level of uncertainty which has been extensively investigated in recent years. A major source of uncertainty inherent to hydraulic model results is linked to the imperfect knowledge of the rainfall input data both in time and space. Several studies show that hydrological modelling in urban areas requires rainfall data with fine resolution in time and space. The present paper analyses the effect of rainfall knowledge on urban flood modelling results. A mathematical model of urban flooding propagation was applied to a real case study and the maximum efficiency conditions for the model and the uncertainty affecting the results were evaluated by means of generalised likelihood uncertainty estimation (GLUE) analysis. The added value provided by the adoption of finer temporal and spatial resolution of the rainfall was assessed.

Mike W. M. Simpson, Diana M. Allen and others (2014): Source-water protection strategies are ideally focused where the greatest amount of harm reduction can occur. This process of risk management requires an assessment of the spatial variability of risk to water. The assessment methodology presented herein combines aquifer susceptibility with a hazard threat inventory and an analysis of the consequence of contamination to assess the risk to water quality. Aquifer 
susceptibility combines the intrinsic susceptibility of the physical system with anthropogenic features that locally increase susceptibility. Hazard threats are assessed based on the properties of the chemicals (toxicity and environmental fate), the potential magnitude (extent and quantity of release) and the likelihood of release. The consequence is herein considered as the financial costs of the loss of the resource, including the replacement of a water source and the economic loss where water intensive businesses are lost. A second scenario is included that analyses health issues related to pathogen sources as well as the financial impact to the community where people fall ill and present a financial burden to the public health care system. The risk assessment methodology is applied to the Township of Langley, in southwestern British Columbia, Canada. The results outline the most vulnerable areas as those where susceptible aquifers coexist with potential chemical and biological threats. The risk is greatest where these vulnerable areas coincide with those with the greatest potential for financial loss: within the capture zones of major municipal production wells and where private wells serve agricultural operations with high annual farm sales.

Lauren E. McPhillips et al. (2014): Groundwater in Chenango County (central New York State, USA) is underlain by Devonian sedimentary bedrock. This region has conventional natural gas wells and is under consideration for future shale gas development using high-volume hydraulic fracturing. The study examines current patterns of dissolved methane in groundwater, based on 113 samples from homeowner wells in the spring of 2012. Samples were analyzed for methane and other water quality parameters, and each well characterized by its landscape position and geology. Statistical testing and regression modeling was used to identify the primary environmental drivers of observed methane patterns. There was no significant difference between methane concentrations in valleys versus upslope locations, in water wells less than or greater than $1 \mathrm{~km}$ from a conventional gas well, and across different geohydrologic units. Methane concentrations were significantly higher in groundwater dominated by sodium chloride or sodium bicarbonate compared with groundwater dominated by calcium bicarbonate, indicating bedrock interactions and lengthy residence times as controls. A multivariate regression model of dissolved methane using only three variables (sodium, hardness, and barium) explained $77 \%$ of methane variability, further emphasizing the dominance of geochemistry and hydrogeology as controls on baseline methane patterns.

Kimberly J. Van Meter, Nandita B. Basu and others (2014): Rainwater harvesting, a "soft path" approach toward water management, is increasingly recognized as a key strategy toward ensuring food security and alleviating problems of water scarcity. Interestingly this "modern" approach has been in use for millennia in numerous older civilizations. This article uses India as a case study to explore the social, economic, and environmental dimensions of agricultural rainwater harvesting ponds, and evaluates the viability of these centuries-old systems under current climate and population pressures. A holistic watershed-scale approach that accounts for trade-offs in water availability and socio-economic wellbeing is recommended for assessing the sustainability of these systems.

Ahmad Zaharin Aris, Wan Ying Lim, Sarva Mangala Praveena and others (2014): The water chemistry of selected rivers in Kota Marudu, Sabah was studied based on the major ion chemistry and its suitability for drinking and irrigation purposes. Ten sampling stations were selected and water samples were collected from each station to assess its chemical properties. 
The physico-chemical variables including temperature, electrical conductivity (EC), total dissolved solids (TDS), salinity, dissolved oxygen (DO), $\mathrm{pH}$, turbidity, ammoniacal-nitrogen (NH3-N), biological oxygen demand (BOD), chemical oxygen demand (COD) and total suspended solid (TSS) were measured. The cations (K, Mg, Ca, Na) were analyzed by ICP-MS. Most of the variables were within the drinking water quality standards stipulated by the World Health Organization (WHO) and the Ministry of Health (MOH), Malaysia except for turbidity. Sodium adsorption ratio (SAR) and salinity hazard were calculated to identify the suitability of the water as irrigation water. The Wilcox diagram classifies that only $10 \%$ of samples are not suitable for the purpose of irrigation. The overall results showed that most of the rivers in Kota Marudu are still in a clean condition and suitable for drinking and irrigation purposes except for Sumbilingan River, which is considered as slightly polluted. The results are supported by the hierarchical cluster analysis as the stations were grouped into two groups; low and high pollution intensities. This preliminary result can update the baseline data of selected water quality parameters in the Kota Marudu and could serve as tool for assisting relevant government bodies in regulating the water resources policies in the future.

Aida Soraya Shamsuddin, Sharifah Norkhadijah Syed Ismail and others (2014): Nitrate is harmful to humans as it can form endogenous nitrosamines which can cause cancer. The major contribution of nitrate contamination in well water is largely from agricultural activities (e.g.; fertilizers and pesticide), wastewater treatment plant discharge, animal yard and manure storage lagoons. Biomarkers such as urine and saliva can be used to determine the occurrence and formation of nitrosamines in the human body. This paper provides an overview of nitrate occurrence in groundwater and the mechanism of nitrosamines formation and its excretion from human body via urine and saliva. The suitability of urine and saliva as biomarkers of endogenous nitrosamines formation were also discussed in this review.

Aditi S. Bhaskar et al. (2015): Subsurface storage as a regulator of streamflow was investigated as an explanation for the large proportion of pre-event water observed in urban streams during storm events. They used multiple lines of inquiry to explore the relationship between pre-event water proportion, subsurface storage, and streamflow under storm conditions. First, they used a three-dimensional model of integrated subsurface and surface flow and solute transport to simulate an idealized hillslope to perform model-based chemical hydrograph separation of stormflow. Second, they employed simple dynamical systems analysis to derive the relationship between subsurface storage and streamflow for three Baltimore, Maryland watersheds (3.8-14 $\mathrm{km}^{2}$ in area) along an urban-to-rural gradient. Last, they applied chemical hydrograph separation to high-frequency specific conductance data in nested urban watersheds $(\sim 50 \%$ impervious surface cover) in Dead Run, Baltimore County, Maryland. Unlike the importance of antecedent subsurface storage observed in some systems, we found that rainfall depth and not subsurface storage was the primary control on pre-event water proportion in both field observations and hillslope numerical experiments. Field observations showed that antecedent stream base flow did not affect pre-event water proportion or streamflow values under storm conditions. Hillslope model results showed that the relationship between streamflow values under storm conditions and subsurface storage was clockwise hysteretic. The simple dynamical systems approach showed that stream base flow in the most urbanized of three watersheds exhibited the largest sensitivity to changes in storage. This work raises questions about the streamflow generation 
mechanisms by which pre-event water dominates urban storm hydrographs, and the shifts between mechanisms in rural and urban watersheds.

Vikrant Vijay Singh, Anupma Sharma and others (2015): The GIS based hydrological model SWAT (Soil and Water Assessment Tool) is applied to a coastal watershed in the water scarce Saurashtra region of Gujarat, India, to understand the rainfall-runoff linkage. The study attempts to identify response of the coastal watershed for existing climatic conditions. The hydrological model is calibrated (2006-2009) and validated (2010-2012) at both daily and monthly scales. Performance of the model during calibration and validation period is evaluated through standard indices, NSE, R2 and PBIAS that indicate an acceptable response. At monthly scale, model performance is good for both low and above average rainfall years.

Donald O. Rosenberry, Jörg Lewandowski, Karin Meinikmann and others (2015): Lake eutrophication is a large and growing problem in many parts of the world, commonly due to anthropogenic sources of nutrients. Improved quantification of nutrient inputs is required to address this problem, including better determination of exchanges between groundwater and lakes. This first of a two-part review provides a brief history of the evolution of the study of groundwater exchange with lakes, followed by a listing of the most commonly used methods for quantifying this exchange. Rates of exchange between lakes and groundwater compiled from the literature are statistically summarized for both exfiltration (flow from groundwater to a lake) and infiltration (flow from a lake to groundwater), including per cent contribution of groundwater to lake-water budgets. Reported rates of exchange between groundwater and lakes span more than five orders of magnitude. Median exfiltration is $0.74 \mathrm{~cm} /$ day, and median infiltration is $0.60 \mathrm{~cm} /$ day. Exfiltration ranges from near $0 \%$ to $94 \%$ of input terms in lake-water budgets, and infiltration ranges from near $0 \%$ to $91 \%$ of loss terms. Median values for exfiltration and infiltration as percentages of input and loss terms of lake-water budgets are $25 \%$ and $35 \%$, respectively. Quantification of the groundwater term is somewhat method dependent, indicating that calculating the groundwater component with multiple methods can provide a better understanding of the accuracy of estimates. The importance of exfiltration to a lake budget ranges widely for lakes less than about 100 ha in area but generally decreases with increasing lake area, particularly for lakes that exceed 100 ha in area. No such relation is evident for lakes where infiltration occurs, perhaps because of the smaller sample size.

Nicolò Colombani et al. (2015): The coastal aquifer salinization is an urgent problem caused by groundwater resources overexploitation and climate change. This phenomenon is enhanced in areas lying below the sea level, like the polders in the Netherlands or the Po River lowland in Italy. In these reclaimed lands the saltwater intrusion is usually controlled by a network of irrigation canals that supplies freshwater to the shallow aquifer, maintaining soil salinity at acceptable levels. The 2012 was dramatic in terms of agricultural water supply, since the Po River plain experienced a prolonged drought. Despite this, continuous monitoring of piezometric heads and total dissolved solids (TDS) near a canal (Canale della Gronda) demonstrated that freshening was occurring in the shallow portion (first $4 \mathrm{~m}$ ) of the unconfined aquifer, while the bottom part was characterized by elevated relic salinity. The two-dimensional model SEAWAT was calibrated using piezometric heads and TDS depth profiles measured along a transect perpendicular to the canal. The calibrated model was then used to predict the behaviour of this cross section using a multiple scenario approach: increase in evapotranspiration induced by 
temperature increase; increase in the frequency of extreme high rainfall events; extreme drought conditions; and canal dewatering due to salinization of the water courses. Moreover, for each scenario, two sub-scenarios were run to account for projected sea level rise. The first three scenarios had only a minor influence on the aquifer salinization rate, while the fourth one predicted serious upward flux of the high salinity groundwater actually residing in the bottom of the unconfined aquifer. The scenarios quantified the possible future effects on groundwater salinization and could be useful to find adaptation strategies to manage the water resources of this and similar areas.

\section{CONCLUDING REMARKS}

Women are not a homogeneous social group. Class, age, religion and ethnicity create important variations in the conditions under which women live, influencing the needs they express, as well as their priorities and demand for water. In general, women comprise an above-average percentage of those designated as poor, but the physical and social realities governing water supply and sanitation are often markedly different. The problems connected with women's roles can therefore vary radically because of geographical context.

Balance in Hydrology is a timely issue widely discussed now. Imbalance in science often comes up from lack of awareness rather than being induced on purpose. Thus, promoting the value and awareness of proportion, in the organization of scientific associations and the community, is a very substantial step ahead. Women have made a significant contribution in the field of Hydrology in recent years. The central challenge, which deserves attention and universal consideration, is to place the appropriate schemes to promote balance without running the risk of artificially boosting.

The role of women needs to be strengthened in developing and using weather, water and climate services. More women should be encouraged to choose a career in meteorology and hydrology, and thus make a vital contribution to the safety and well-being of society. As we build weather and climate resilient societies, we absolutely require the critical leadership and involvement of women. We need them as scientific researchers, as key actors in disaster risk reduction, climate adaptation and mitigation, as agents of change. And we must start by expanding women's participation in science, technology, engineering and mathematics, and developing gender equality strategies in educational institutions and hydrological services.

\section{REFERENCES}

[1] Aditi S. Bhaskar and Claire Welty. Water Balances along an Urban-to-Rural Gradient of Metropolitan Baltimore, 2001 - 2009. Environmental \& Engineering Geoscience. Vol. XVIII, No. 1, 2012, 37-50.

[2] Aditi S. Bhaskar and Claire Welty. Analysis of Subsurface Storage and Streamflow Generation in Urban Watersheds. Water Resources Research. Vol. 51, Issue 3, March 2015, 1493-1513.

[3] Ahmad Zaharin Aris, Wan Ying Lim, Sarva Mangala Praveena, Mohd Kamil Yusoff, Muhammad Firuz Ramli, Hafizan Juahir. Water Quality Status of Selected Rivers in Kota 
Marudu, Sabah, Malaysia and its Suitability for Usage. Sains Malaysiana. Vol. 43, No. 3, 2014, 377-388.

[4] Aida Soraya Shamsuddin, Sharifah Norkhadijah Syed Ismail, Shaharuddin Mohd. Sham, Emilia Zainal Abidin. Nitrate in Groundwater and Excretion of Nitrate and Nitrosamines in Urine: A Review. International Journal of Sciences: Basic and Applied Research (IJSBAR). Vol. 15, No. 2, 2014, 176-91.

[5] Archana Sarkar, Rakesh Kumar. Artificial Neural Networks for Event Based RainfallRunoff Modeling. Journal of Water Resource and Protection, 4, 2012, 891-897.

[6] A. Z. Aris, S. M. Praveena, M. H. Abdullah \& M. Radojevic. Statistical Approaches and Hydrochemical Modelling of Groundwater System in a Small Tropical Island. Journal of Hydroinformatics. Vol. 14, No. 1, 2012, 206-220.

[7] Bridget R. Scanlon, Claudia C. Faunt, Laurent Longuevergne, Robert C. Reedy, William M. Alley, Virginia L. McGuire \& Peter B. McMahon. Groundwater Depletion and Sustainability of Irrigation in the US High Plains and Central Valley. PNAS. Vol. 109, No. 24, June 2012, 9320-25.

[8] Bridget R. Scanlon, Ian Duncan \& Robert C Reedy. Drought and the Water-Energy Nexus in Texas. Environmental Research Letters, Vol. 8, 2013, 1-15.

[9] C. Isabella Bovolo, Geoff Parkin \& Marios Sophocleous. Editorial: Groundwater Resources, Climate and Vulnerability. Environmental Research Letters. Vol. 4, No. 3, 2009.

[10] Donald O. Rosenberry, Jörg Lewandowski, Karin Meinikmann and Gunnar Nützmann. Groundwater - The Disregarded Component in Lake Water and Nutrient Budgets. Part 1: Effects of Groundwater on Hydrology. Hydrological Processes, 2015.

[11] Etishree Agarwal, R. D. Garg and P. K. Garg. Delineation of Groundwater Potential Zone: An AHP/ANP Approach. Journal of Earth System Science. Vol. 122, No. 3, 2013, 887-898.

[12] Firdes Yenilmez, Fatih Keskin and Aysegul Aksoy. Water Quality Trend Analysis in Eymir Lake, Ankara. Physics and Chemistry of the Earth, Vol. 36, 2011, 135-140.

[13] G. Freni, G. La Loggia and V. Notaro. Uncertainty in Urban Flood Damage Assessment due to Urban Drainage Modelling and Depth-Damage Curve Estimation. Water Science and Technology, Vol. 61, No. 12, 2010, 2979-2993.

[14] I. Delpla, A. V. Jung, E. Baures, M. Clement and O. Thomas. Impacts of Climate Change on Surface Water Quality in relation to Drinking Water Production. Environment International. Vol. 35, 2009, 1225-1233.

[15] Justine He'nonin, Hongtao Ma, Zheng-Yu Yang, Johan Hartnack, Karsten Havn, , Philippe Gourbesville and Ole Mark. Citywide Multi-grid urban Flood Modelling: The July 2012 Flood in Beijing. Urban Water Journal. 2013, 1-15.

[16] Kimberly J. Van Meter, Nandita B. Basu, Eric Tate and Joseph Wyckoff. Monsoon Harvests: The Living Legacies of Rainwater Harvesting Systems in South India. Environmental Science and Technology. Vol. 48, No. 8, 2014, 4217-25.

[17] Lauren E. McPhillips, Anne Elise Creamer, Brian G. Rahm and M. Todd Walter. Assessing Dissolved Methane Patterns in Central New York Groundwater. Journal of Hydrology: Regional Studies. 2014, 57-73.

[18] Mike W. M. Simpson, Diana M. Allen, Murray M. Journeay. Assessing Risk to Groundwater Quality using an Integrated Risk Framework. Environmental Earth Sciences. Vol. 71, 2014, No. 11. 
[19] Nicolò Colombani, Micòl Mastrocicco and Beatrice Maria Sole Giambastiani. Predicting Salinization Trends in a Lowland Coastal Aquifer: Comacchio (Italy). Water Resources Management. Vol. 29, No. 2, 2015, 603-618.

[20] Sujana Dhar and Asis Mazumdar. Hydrological Modelling of the Kangsabati River under Changed Climate Scenario: Case Study in India. Hydrological Processes. Vol. 23, No. 16, 2009, 2394-2406.

[21] UN-Women and UNW-DPAC. Women as Agents of Change in Water - Reflections on Experiences from the Field, Women for Water Partnership, June 2015, 62 p.

[22] Vikrant Vijay Singh, Anupma Sharma, P.C. Joshi. Modelling of Runoff Response in a Semi-arid Coastal Watershed using SWAT. International Journal of Engineering Research and Applications. Vol. 5, Issue 6, 2015, 50-57.

[23] Vincenza Notaro, Chiara Maria Fontanazza, Gabriele Freni, Valeria Puleo. Impact of Rainfall Data Resolution in Time and Space on the Urban Flooding Evaluation. Water Science and Technology. Vol. 68, No. 9, 2013, 1984-93.

[24] World Meteorological Organization. Report of the Second WMO Conference on Women in Meteorology and Hydrology. Geneva, 24-27 March, 2003.

[25] World Meteorological Organization. Gender Equality in the Caribbean - A Continuing Challenge for Science. MeteoWorld, April 2008.

[26] World Meteorological Organization - Bulletin. Women working in Meteorology and Hydrology. 2003. 